\title{
From Acceptance to Adaptive Acceptance of Social Media Policy Change: a Set-Theoretic Analysis of B2B SMEs
}

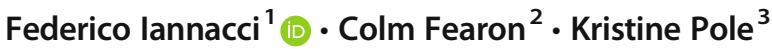 \\ Published online: 6 February 2020 \\ (C) The Author(s) 2020
}

\begin{abstract}
Drawing on theories of mindfulness, this paper aims to introduce the concept of adaptive acceptance of social media policy change in the context of Business-to-Business (B2B) Small-and-Medium Enterprises (SMEs) based in the South East of England. The paper adopts a quasi-experimental design based on the analysis of multiple cases with each case replicating prior findings either literally or theoretically. The study uses a mix of survey, interview, and electronic data informed by an innovative, settheoretic approach to distill commonalities within positive cases and differences between positive and negative cases. It shows that attracting new customers and raising the company's profile are necessary pre-requisites for adaptive acceptance of social media policy changes. In addition, these two conditions combined with learning to use social media effortlessly are jointly sufficient for adaptive acceptance. Theoretical, practical, and methodological implications are discussed.
\end{abstract}

Keywords Qualitative comparative analysis · Configurational theory $\cdot$ Small-and-medium enterprises $\cdot$ Social media Mindfulness

\section{Introduction}

Social media are Internet-based applications that employ mobile and web-based technologies to create highly-interactive platforms that allow the generation and exchange of user-

Electronic supplementary material The online version of this article (https://doi.org/10.1007/s10796-020-09988-1) contains supplementary material, which is available to authorized users.

Federico Iannacci

F.Iannacci@sussex.ac.uk; fiannacci@hotmail.com

Colm Fearon

C.Fearon@bham.ac.uk

Kristine Pole

kristine.pole@ canterbury.ac.uk

1 Department of Management, Business School, University of Sussex, Jubilee Building, BN1 9SL, Falmer, Brighton, UK

2 Department of Management, Birmingham Business School, University of Birmingham, University House, Birmingham B15 2TT, UK

3 Faculty of Social \& Applied Sciences, Business School, Canterbury Christ Church University, North Holmes Road, Canterbury CT1 1QU, UK generated content (Kaplan and Haenlein 2010). Compared with traditional communication tools, social media enable organizations to bypass the trade-off between univocality and multivocality, reach and richness, and production and consumption (Huang et al. 2013). Furthermore, they allow organizations to engage in timely, open, and interactive conversations with customers at relatively-low costs (Kaplan and Haenlein 2010; Kwayu et al. 2018). As such, they are particularly appealing to SMEs because SMEs are notoriously short of resources and funding (Järvinen et al. 2012). Web 2.0 tools and applications enable SMEs to leverage their internal and external competences, reduce the need for costly IT infrastructure, and facilitate rapid internationalization (Bell and Loane 2010). Hence, studying social media use by SMEs is a crucial step toward understanding how SMEs can cut costs, operate more efficiently, and be more competitive in a highly-dynamic business environment (Kim et al. 2013).

However, the use of social media is particularly challenging in the Business-to-Business (B2B) SME context (Jussila et al. 2014; Michaelidou et al. 2011). Despite the smaller number of customers, B2B SMEs are bound to engage with larger business partners than their Business-to-Consumer (B2C) counterparts. Such larger business partners, in turn, can make more specialized demands, engage in more direct and intense communications with B2B SMEs, and be more 
conservative with regard to security and privacy issues (Heidt et al. 2019). Furthermore, social media privacy policies and terms of service are in a constant state of flux. ${ }^{1}$ While in some cases social media policy changes may be trivial, in other cases such changes may be quite radical because they can reshape the rules of the game (e.g., by affecting the visibility of information posted on social media, the persistence and durability of content over time, etc.). These changes, in turn, add a layer of complexity that goes beyond the technical side because they are about the soft side of social media rather than the hard side of new features and applications.

Given the challenges arising from the use of social media in the SME setting in general and the B2B SME context in particular, understanding the causes underpinning B2B SMEs' adaptation to social media policy changes is strategically important. Though adaptation may be thought of as an integral part of the mindful use of social media (Swanson and Ramiller 2004), very few studies have focused on the mindful use of social media in business settings (Culnan et al. 2010; Poston and Kettinger 2014). Arguably, mindful social media use extends beyond the initial adoption decision. Indeed, it is likely that post-adoption decisions will revolve around some form of reinvention of the initial adoption decision. Social media use is disrupted by ongoing disturbances in terms of new social media policies, features, and applications. While new features and applications act as enablers, social media policy changes can trigger a higher level of complexity because they may hide threats that may undermine existing business models.

For example, based on the European Union's data protection regulation, Google announced the unification of all its privacy policies in 2012 (Fuchs 2014), thus making it more difficult to keep personal and professional accounts separate. Likewise, Twitter's policies grew in length and complexity over time to the point that the company set out nonexclusive licensing rights with respect to user-generated content in 2011 (Ibid). More recently, Facebook, Google, LinkedIn and Twitter have updated their social media policies to comply with the General Data Protection Regulation (GDPR 2016) that applies to all companies that process personal data about individuals in the European Union regardless of where the company is based. Far from being backwardlooking guidelines, social media policies encompass the overall ensemble of features including new features added to existing social media platforms. By accessing or using these features, users agree to be bound by these policies and their radical effects (e.g., losing control over sensitive information such as intellectual property and proprietary knowledge, breaching customers' confidentiality by disclosing their contact details in the public domain, undermining the company's brand by associating personal postings with the corporate

\footnotetext{
${ }^{1}$ Hereafter, we use the umbrella term "social media policies" to refer to social media privacy policies and terms of service.
}

brand, etc.). In this study we build on and extend past technology-acceptance research (Beaudry and Pinsonneault 2005; Burton-Jones and Grange 2013; Mandal and McQueen 2012). While extant research argues that postadoption perceptions of usefulness (extrinsic rewards) and ease of use (intrinsic effort) play a key role in terms of postadoption decisions (Venkatesh et al. 2011), we develop a new concept of acceptance that is more sensitive to the disruptive effects arising from (some) social media policy changes.

Drawing on theories of mindfulness (Carlo et al. 2012; Levinthal and Rerup 2006; Swanson and Ramiller 2004; Thatcher et al. 2018; Weick et al. 1999), we introduce a new concept, that is, adaptive acceptance, which is more in tune with the dynamic nature of social media platforms. By adaptive acceptance, we mean the degree to which B2B SMEs promptly accept and adapt to ongoing social media policy changes in order to "cope with and respond to change swiftly" (Weick and Sutcliffe 2007: 73). Against this background, our two-fold research question (RQ) asks:

\section{1) What are the causal factors that are relevant for $B 2 B$ SMEs' adaptive acceptance of social media policy changes? 2) In what way do these factors combine to produce the outcome of interest?}

In what follows, we develop a model of post-adoption decisions by microbusinesses in a set-theoretic fashion to study the adaptive acceptance of social media policy changes by B2B SMEs. Though technology-acceptance theories have recently been extended to post-adoption decisions (Venkatesh et al. 2011), scholars are yet to explore issues of mindful use of social media in the B2B SME context (Poston and Kettinger 2014). Our findings demonstrate the relevance of ease of learning beyond the initial stages of adoption. Ease of learning counteracts the cognitive effort stemming from attracting new customers and raising the company's profile, thus freeing cognitive energy for coping with complex policy changes more adaptively (or mindfully).

The remainder of this paper unfolds as follows. Section Two reviews extant literature on technology acceptance and mindfulness to develop a post-adoption model of adaptive acceptance of social media policy change by B2B SMEs. Section Three outlines our set-theoretic approach, our data analysis technique, and the data collection methods. Section Four presents our findings. Section Five analyzes our findings by emphasizing the importance of ease of learning in a context where B2B SMEs have to cope with radical policy changes while using social media for attracting new customers and raising their profile. Finally, Section Six summarizes the main theoretical, practical, and methodological implications of our work while highlighting its limitations. The online appendix illustrates a glossary of key terms used in set-theoretic analyses, as well as several robustness tests to validate our findings. 


\section{Theoretical Background: The Post-Adoption Model of Adaptive Acceptance of Social Media Policy Change by B2B SMEs}

The Technology Acceptance Model (TAM) is a native IS theory (Straub 2012) and is probably one of the most cited reference frameworks in the field of information systems (Lee et al. 2003). Drawing on the theory of reasoned action (Ajzen and Fishbein 2000), TAM simply and parsimoniously predicts that technology usage is determined by behavioral intention which, in turn, is jointly and separately affected by the individual's attitude toward using the system and perceived usefulness. Both perceived usefulness and attitude, in turn, are affected by perceived ease of use and a host of external variables impinging upon perceived usefulness and perceived ease of use (Davis 1989; Davis et al. 1989; Dwivedi et al. 2019; Venkatesh and Davis 2000).

Adapting individual-level frameworks to studies of technology acceptance by SMEs is justifiable as the individual and firm levels are more closely related than for larger firms $(\mathrm{Li}$ et al. 2011). Additionally, although survey items can capture collective intentions in terms of "we-intentions" (Bagozzi 2000; Shen et al. 2011), new technologies in general and social media in particular have been hypothesized to raise new challenges and opportunities for TAM and its extensions (Günther et al. 2009). For example, it has been argued that, compared with traditional objects of analysis in TAM research, social media use entails data security and privacy concerns, self-disclosure, social interactions and a higher degree of collaboration (Chiu et al. 2011; Dwivedi et al. 2018). Hence, TAM and its extensions have been modified to account for the specific challenges and opportunities raised by social media use. In particular, communication benefits in terms of improved information flows have been identified to be the most important dimensions of perceived usefulness (Günther et al. 2009). Furthermore, in the context of microbusinesses, owner characteristics and perceived ease of use coupled with perceived usefulness have been suggested to influence social media acceptance in a two-way fashion (Mandal and McQueen 2012).

More specifically, Mandal and McQueen (2012) have argued that during the initial adoption process, social influence and facilitating conditions have a moderating effect in the decision to adopt the tool. On adoption of the tool, owner characteristics, post-adoption perceptions of ease of use, and usefulness will interact to play a dominant role in deciding the intensive use of the tool (Ibid). Given that there can be causal relationships among these three variables (Ibid) and considering that our sample of early-adopter B2B SMEs (Rogers 2003) used social media tools to participate in the study, we regard owners'/managers' personal-innovativeness traits as boundary conditions and investigate within such boundaries the complex interaction effects between the dimensions of perceived ease of use and perceived usefulness.
Drawing on extant literature (e.g., Mandal and McQueen 2012; Paluch et al. 2015; etc.), we expect that perceived usefulness is positively associated with B2B SMEs' adaptive acceptance of social media policy changes. Nevertheless, perceived ease of use may be negatively associated because it may be synergistic with the effort (or sacrifice) stemming from the complexity of using social media technologies ( $\mathrm{Hu}$ et al. 2015). On the one hand, social media potential to attract new customers (Michaelidou et al. 2011), increase awareness (Ibid), and enhance business performance (e.g., Siamagka et al. 2015) raises the degree of perceived usefulness and positively contributes to a mindful use of social media aimed at maximizing these benefits. On the other hand, the effort required for interacting with social media, learning to use social media, and becoming skillful at using social media can undermine the advantages stemming from an enhanced usefulness because active engagement of business customers can make social media too complex for B2B users (Paluch et al. 2015). In other words, we conjecture that perceived ease of use and perceived usefulness may work in opposite and at times unexpected directions (Siamagka et al. 2015: 93-95), thus requiring a more granular understanding of the multiple combinations of causal conditions leading to adaptive acceptance. ${ }^{2}$

\subsection{The Post-Adoption Model of Adaptive Acceptance and its Links with Mindfulness Theory}

Adaptive acceptance captures the degree to which B2B SMEs promptly accept and adapt to ongoing social media policy changes in order to "cope with and respond to change swiftly" (Weick and Sutcliffe 2007: 73). The concept of adaptive acceptance overlaps with the notion of mindfulness to a large degree (Carlo et al. 2012; Levinthal and Rerup 2006; Swanson and Ramiller 2004; Thatcher et al. 2018; Weick et al. 1999). Not only is mindfulness a core dimension in the adaptive use of social media. It also requires "attentiveness to one's context, as well as the capacity to respond to unanticipated cues or signals from one's context" (Levinthal and Rerup 2006: 504). Akin to Levinthal and Rerup's (2006) notion of mindfulness, adaptive acceptance then captures perceptual information about cognitive and behavioral aspects. The cognitive aspect is about being alert and attentive to the risks stemming from changing social media policies. The behavioral aspect is about responding to unexpected policy changes quickly (e.g., changing privacy settings, upgrading security systems, introducing new governance arrangements, etc.). Furthermore, from a methodological perspective, adaptive acceptance

\footnotetext{
${ }^{2}$ Another way of framing the issue is in terms of extrinsic benefits vs. intrinsic complexity (Gefen and Straub 2000). Social media use is instrumental to specific goals (e.g., raising the company's profile, enhancing business performance, and attracting new business customers). While these goals are extrinsic to social media, using social media skillfully and in an educated and interactive fashion are tasks intrinsic to social media.
} 
draws on "the concept PLUS attributes" approach (Beach and Pedersen 2016: 106-108). Accordingly, one needs to put an adjective such as "adaptive" in front of the concept of acceptance to mark the addition of one specific attribute, namely "adaptiveness" or "mindfulness", that divides the cases under investigation into two distinct sub-groups with distinctive causal properties (Ibid). This is because the combination or configuration of causal conditions leading to adaptive acceptance need not be simply the reverse of the configurations for non-adaptive acceptance. Therefore, it is methodologically appropriate to theorize subtypes of a broader concept (Ibid), namely, the concept of acceptance itself. Figure 1 below exemplifies the concept of acceptance and its set-theoretic subtypes.

Another way to introduce the concept of adaptive acceptance is to look at its opposite concept, that is, routinized acceptance. Though acceptance is an ambiguous term, Saga and Zmud (1993: 69) define the root term "accept" as "the act of receiving information technology use willingly." A B2B SME may willingly receive changes to social media policies without transforming its business practices. This would be equivalent to a mindless or automated decision where business as usual prevails at the expense of unlocking the potential of these changes or, in the extreme case, losing control over sensitive information. Hence, adaptive acceptance captures B2B SMEs' capability to make sense of (accept) and respond (adapt) to ongoing social media policy changes quickly. Far from being passive organizations, B2B SMEs that accept and adapt to ongoing social media policy changes quickly are truly mindful (Carlo et al. 2012; Levinthal and Rerup 2006; Swanson and Ramiller 2004; Thatcher et al. 2018; Weick et al. 1999). Such SMEs are constantly monitoring social media policy changes with the purpose of reinventing their existing practices accordingly. Figure 2 below depicts the post-adoption model of adaptive acceptance.

It is worth stressing that the post-adoption model of adaptive acceptance displayed above assumes that learning is the cumulative development of procedural knowledge (know how) while adaptation refers to a response to ecological (or environmental) disturbances geared toward the development of declarative (or explicit) knowledge (e.g., new governance

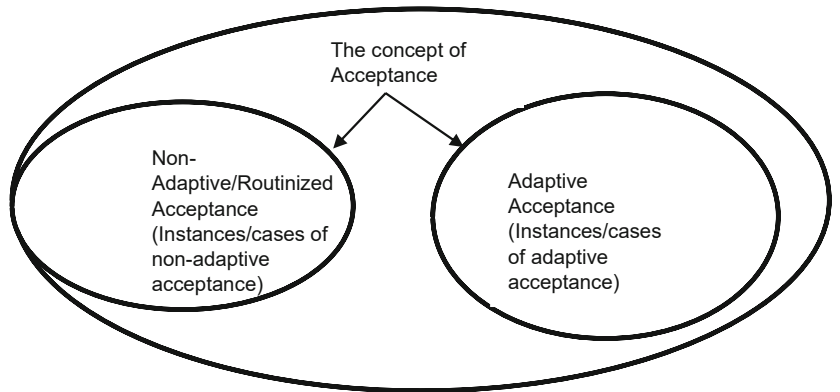

Fig. 1 The concept of acceptance and its set-theoretic subtypes (Adapted from Beach and Pedersen 2016) arrangements, new privacy policies, new security settings, etc.). Furthermore, the model assumes that there are two types of disturbances that can be out of synch with each other, namely social media policy changes and new features or applications, the former requiring a concerted strategy, the latter impinging on the consequences of the use (or adoption) of social media. Since mindful (or adaptive) B2B SMEs are preoccupied with failure (Weick and Sutcliffe 2007), they tend to bracket (and make sense of) social media policy changes because these environmental disturbances may hide risks that threaten their business model.

Rather than investigating the initial adoption process, in this study we focus on post-adoption decisions framed in terms of quick acceptance and adaptation to complex social media policy changes. If facilitating conditions are satisfied and social influence processes are in motion in the industry where B2B SMEs operate (Siamagka et al. 2015), the adoption decision is straightforward in the context of social media because there are virtually no costs involved (Bharati et al. 2014). Hence, we shift our focus from adoption to post adoption.

\section{Methodology: The Set-Theoretic Approach and the Data Collection Methods}

Given our interest in the way causes combine to determine B2B SMEs' adaptive acceptance of social media policy changes, we deployed Qualitative Comparative Analysis (QCA) techniques that articulate our causal expectations in set-theoretic terms (Ragin 2008; Schneider and Wagemann 2012). Set theory aims at separating a group (or set) of elements from everything else based on a criterion of membership (Mingers 2006). For example, based on whether (or not) the SME in question had accepted and adapted to social media policy change quickly, we identified two separate types of cases, namely cases of adaptive and routinized acceptance respectively.

We designed our study by using the indirect method of difference which consists of a double application of the method of agreement (Beach and Pedersen 2016; George and Bennett 2005). Essentially, we first searched for similarities across cases that might account for similar outcomes in terms of adaptive acceptance. We then searched for differences across cases that might account for differences across outcomes (i.e., adaptive acceptance vs. routinized acceptance). Thus, we deemed cross-case commonalities to be irrelevant when moving from positive cases (i.e., adaptive acceptance) to negative cases (i.e., routinized acceptance) because conditions present in both types of cases cannot account for differences in case outcomes. This approach mirrors the replication logic used for quasi-experimental designs (Yin 2014). The search for similarities helps one predict similar results (i.e., 
Fig. 2 The post-adoption model of adaptive acceptance of social media policy change by B2B SMEs. Adapted from Beaudry and Pinsonneault (2005), BurtonJones and Grange (2013), and Mandal and McQueen (2012)

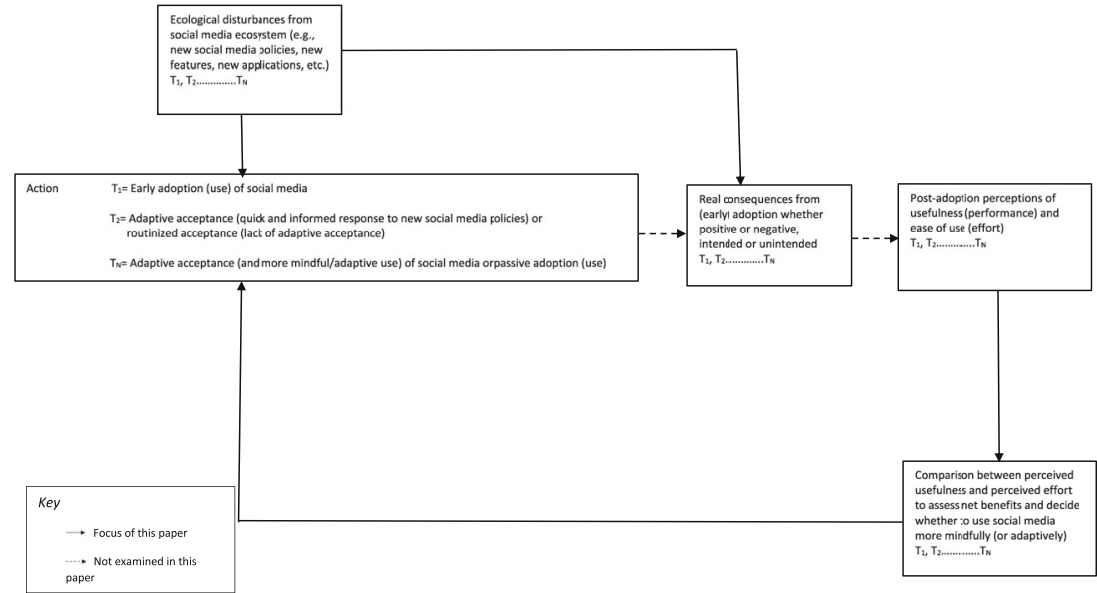

literal replication). The search for differences helps one predict contrasting results in terms of adaptive acceptance vs. routinized acceptance but for anticipatable reasons (i.e., theoretical replication).

Set-theoretic methods identify two types of causal relations, namely relations of causal necessity and sufficiency. Causal necessity implies a superset relation between causal conditions (or combinations of causal conditions) and outcomes because the empirical instances of the outcome are outnumbered by the instances of the cause (Mahoney and Vanderpoel 2015). For example, the group of B2B SMEs that accept and adapt to social media policy change quickly is a rough subset of the group of B2B SMEs that find that social media have helped them attract new customers in Fig. 3. Being mindful of ongoing social media policy changes requires that B2B SMEs find social media useful in terms of attracting new customers (Michaelidou et al. 2011). There is no point in being mindful of complex policy changes if B2B SMEs perceive social media as being unhelpful when it comes to attracting new customers. More traditional face-to-face networking will be prioritized in this context at the expense of social media. Hence, on the basis of recent theories of postadoptive use of IT tools in general (Venkatesh et al. 2011) and cognitive response in B2B settings in particular (Paluch et al. 2015), one can argue that attracting new customers is a necessary but not sufficient cause for adaptive acceptance. Whenever we see instances of the outcome we almost always

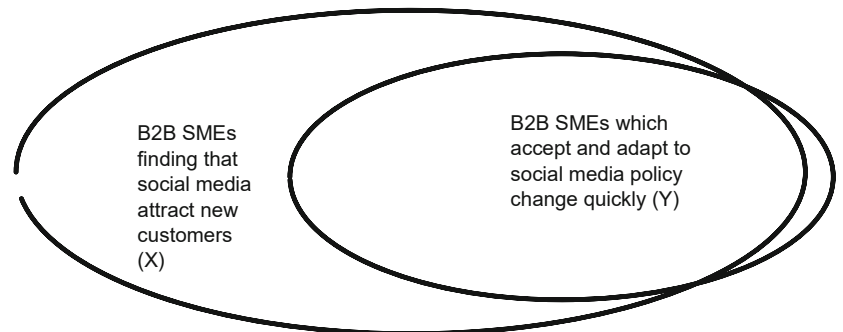

Fig. 3 Venn diagram illustration of causal necessity for dichotomous crisp sets see instances of the cause but we might also see instances of the necessary cause without the outcome. Figure 3 displays this set-theoretic relation for dichotomous crisp sets.

The same relation can be captured with an X, Y plot in the case of fuzzy sets. Fuzzy sets allow for partial membership in addition to full membership and full non-membership in the target set. Parallel to crisp sets where the larger set indicates the necessary cause, each case fuzzy-set membership score in attracting new customers (i.e., the cause $\mathrm{X}$ ) must be equal to or larger than its fuzzy-set membership score in the outcome $\mathrm{Y}$ (i.e., accepting and adapting to social media policy change quickly). Figure 4 displays a perfect set-theoretic relation in the case of fuzzy sets.

Conversely, sufficiency entails a subset relation between causal conditions (or combinations of causal conditions) and the outcome because the empirical instances of the cause are fewer than the empirical instances of the outcome. For example, the group of B2B SMEs that find that social media have helped the company attract new customers and simultaneously raise its profile and enhance its business performance is a rough subset of the group of B2B SMEs that accept and adapt to social media policy change quickly in Fig. 5. These B2B SMEs should be mindful of potential disturbances that may threaten their business model. They should be willing to understand new social media policies and adapt their practices accordingly. Hence, on the basis of theories of post-adoptive IT use in general (Venkatesh et al. 2011) and cognitive

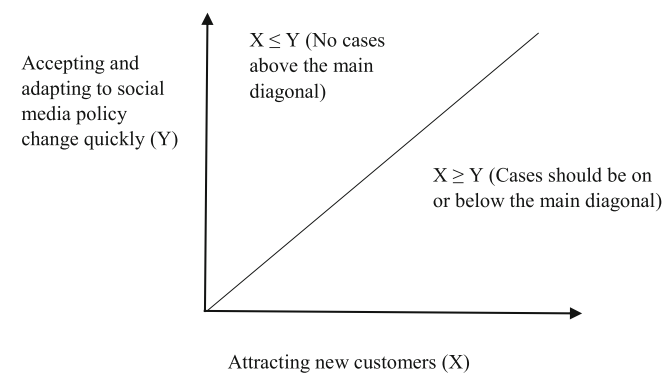

Fig. $4 \mathrm{X}$, Y plot distribution of cases for necessary condition 
response in B2B settings in particular (Paluch et al. 2015), one can argue that whenever we see B2B SMEs that perceive that social media have helped them attract new customers while raising their profile and enhancing their business performance, we almost always see B2B SMEs accepting and adapting quickly to social media policy changes. Nevertheless, instances of quick acceptance and adaptation may occur for other reasons. Figure 5 displays this set-theoretic relation for dichotomous crisp sets.

Once again, the same relation of causal sufficiency can be displayed with an X, Y plot. Figure 6 below displays a perfect relation of sufficiency between attracting new customers AND raising the company's profile AND enhancing business performance (i.e., the cause $\mathrm{X}$ ) and the outcome Y (i.e., accepting and adapting to social media policy change quickly).

QCA is simultaneously a set-theoretic approach and a group of techniques aimed at unraveling causal complexity (Rihoux and Lobe 2009). As a set-theoretic approach, QCA interweaves the case-oriented logic of qualitative research with the variance-oriented logic of quantitative research seeking explanations in terms of independent (or causal) variables being associated with the dependent (or outcome) variable (Ragin 1987). QCA's set-theoretic logic is diversity-oriented because the sample under investigation is not viewed as a homogeneous representation of a wider population but as a heterogeneous collection of different types, subtypes, and mixed types of configurations (or patterns). Hence, this settheoretic approach entails the discovery of several, mutually non-exclusive pathways leading to the outcome of interest with each pathway corresponding to a particular configuration or combination of causal conditions resembling an overall type of case (Fiss 2011).

Given the diversity-oriented and exploratory hallmark of QCA (Ragin 2000) and considering the growing body of research on social media (Aral et al. 2013; Kane et al. 2014; Kapoor et al. 2018; Kim et al. 2013; Leonardi et al. 2013; Wang et al. 2016), we undertook a theory-enhanced Qualitative Comparative Analysis (QCA) that was informed by our theoretical expectations about the linkages between causal (or independent) and outcome (or dependent) variables (Schneider and Wagemann 2012). Hence, we uncovered

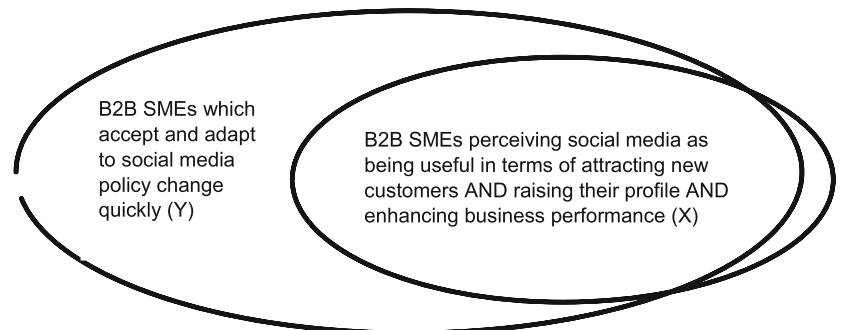

Fig. 5 Venn diagram illustration of causal sufficiency for dichotomous crisp sets

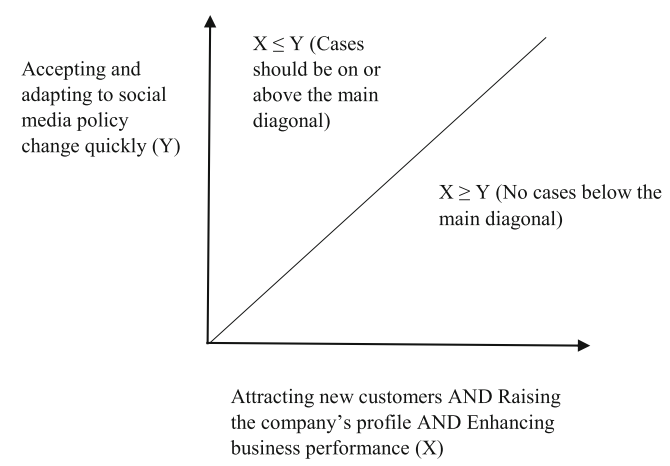

Fig. $6 \mathrm{X}$, Y plot distribution of cases for sufficient condition

multiple and partially-overlapping combinations of causal conditions in our sample which were subsequently simplified with the inclusion of counterfactuals (or "thought experiments") that met our theoretical expectations about necessary and sufficient conditions (Ibid). This process helped us develop new insights that were taken as a basis for further theory development (Berg-Schlosser et al. 2009). Figure 7 breaks down the QCA approach deployed in this paper in a stepwise fashion.

\subsection{The Analytical Technique}

Set-theoretic approaches are based on a specific template to undertake data analysis. This template requires three steps (Schneider and Wagemann 2012).

Step 1: Calibration First, causal conditions and outcome variables must be calibrated through the assignment of appropriate set-membership scores based on specific anchor points (Ragin 2008). Subsequently, these set measures are used to construct a truth table with $2^{\mathrm{k}}$ rows, where $\mathrm{K}$ is the number of causal conditions used in the analysis. The truth table is an analytical device that lists all logically-possible combinations of causal conditions both present and absent with their associated outcomes (Schneider and Wagemann 2012). The empirical cases can then be assigned to these rows based on their values for the causal conditions, with some rows containing many cases, some rows just a few, and some rows containing no cases at all.

One of the main problems with truth-table analysis is that the number of logical combinations increases exponentially with the number of causal conditions because the binary possibilities correspond to $2^{\mathrm{k}}$ where $\mathrm{K}$ indicates the number of conditions. As the number of logically-possible combinations increases, so does the number of remainders or empty rows. Researchers, therefore, should keep the number of causal conditions to a reasonable minimum. Following Ragin's (2008) advice and drawing on extant theory of technology acceptance in general (Gefen and Straub 2000) and adoption of social media by B2B SMEs in particular 
Fig. 7 A high-level view of the QCA approach deployed in this paper (Adapted from Rihoux and Lobe 2009)

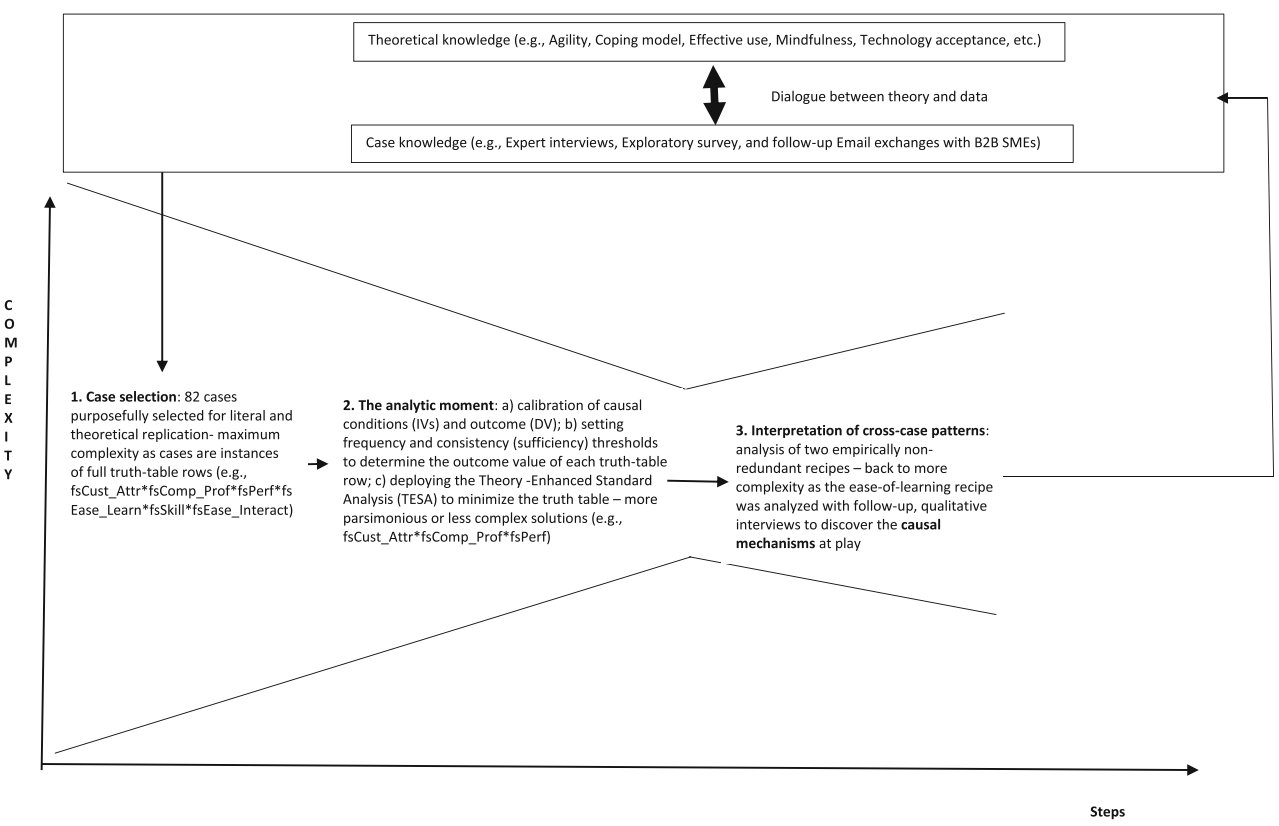

(Michaelidou et al. 2011), we used only six causal conditions, namely:

1. Enhancing business performance: past research has demonstrated that organizational performance is a determinant of adoption of communication technologies whenever such technologies are used as a means to achieve extrinsic outcomes (Gefen and Straub 2000). More recently, scholars have confirmed this relationship in the B2B social media context (Siamagka et al. 2015). Accordingly, we expect that enhancing business performance will be a determinant of post-adoption decisions (Venkatesh et al. 2011) because social media in general and Web 2.0 technologies in particular fall within the communication technologies' umbrella (Park et al. 2017).

2. Attracting new customers: past research has demonstrated that B2B SMEs in the UK are using social networking sites to achieve brand objectives, the most popular of which is to attract new customers (Michaelidou et al. 2011). Furthermore, prior expert interviews with the Managing Director of the company that administered the survey (i.e., Alpha, a pseudonym) corroborate the relevance of customer attraction as a determinant of post-adoption decisions.

3. Raising the company's profile: past research has demonstrated that B2B SMEs in the UK are using social networking sites to increase awareness and raise their profile (Michaelidou et al. 2011). Again, prior expert interviews with Alpha's Managing Director do corroborate the relevance of raising the company's profile as a determinant of post-adoption decisions.

4. Ease of learning to use social media: past research has demonstrated that ease of learning plays a crucial role as a determinant of adoption of communication technologies in relation to tasks or goals that are intrinsic to such technologies (Gefen and Straub 2000). Accordingly, we conjectured that ease of learning is a determinant of post-adoption decisions (Venkatesh et al. 2011) because social media in general and Web 2.0 technologies in particular fall within the communication technologies' umbrella (Park et al. 2017).

5. Skillfulness at using social media: past research has demonstrated that skillfulness plays a crucial role as a determinant of adoption of communication technologies in relation to tasks or goals that are intrinsic to such technologies (Gefen and Straub 2000). Accordingly, we expect that becoming skillful at using social media will be a determinant of post-adoption decisions (Venkatesh et al. 2011) because social media in general and Web 2.0 technologies in particular fall within the communication technologies' umbrella (Park et al. 2017).

6. Ease of interaction with social media: past research has demonstrated that ease of interaction plays a crucial role as a determinant of adoption of communication technologies in relation to tasks or goals that are intrinsic to such technologies (Gefen and Straub 2000). Accordingly, we expect that finding social media easy to interact with will be a determinant of post-adoption decisions (Venkatesh et al. 2011) because social media in general and Web 2.0 technologies in particular fall within the communication technologies' umbrella (Park et al. 2017). ${ }^{3}$

\footnotetext{
${ }^{3}$ Though we are formulating directional expectations here limited to single conditions, in the remainder of this paper we formulate conjunctural directional expectations on empty (or remainder) rows, that is, directional expectations on conjunctions of conditions (Cf. Schneider and Wagemann 2012: 215-217). Compared with the Standard Analysis, this practice is more in tune with QCA focus on multiple conjunctural causation (Ibid).
} 
Our outcome variable ("Adaptive Acceptance") instead was measured in terms of the degree to which the B2B SME in question accepts and adapts to social media policy change quickly. The outcome variable was measured using one single survey item (Emmenegger et al. 2014; Siamagka et al. 2015: 92 ) with "equidistant membership values" for calibration purposes (Liu et al. 2017: 68; footnote 1). It was adapted from Srinivasan's et al. (2002: 52) notion of "technology responsiveness" (i.e., "My company accepts and adapts to social media policy change quickly"). ${ }^{4}$ Table 1 highlights the survey items used for the determinants of Adaptive Acceptance.

Drawing on existing research (Aral et al. 2013; Kane et al. 2014; Kapoor et al. 2018; Kim et al. 2013; Leonardi et al. 2013; Mandal and McQueen 2012; Michaelidou et al. 2011; Wang et al. 2016) and prior interviews held with Alpha's Managing Director, we conceived of perceived usefulness and perceived ease of use as a combination of conditions that are individually necessary and jointly sufficient for concept formation (Goertz and Mahoney 2012). This, in turn, meant that these conditions could be "theorized to interact with each other in complex ways, such as by boosting each other's causal effects" (Beach and Pedersen 2016: 105).

Each condition was measured on a five-point scale ranging from "strongly disagree" to "strongly agree." These conditions were subsequently coded from 1 to 5 with $1=$ "strongly disagree," $3=$ "neither agree nor disagree," $5=$ "strongly agree" as the three anchor points. Such single-item scales were then calibrated using Ragin's (2008) direct method of calibration as this method is available in the fuzzy-set Qualitative Comparative Analysis (fsQCA) 2.5 software and can be applied whenever rating-scale variables are at hand (Ragin 2008; Schneider and Wagemann 2012). Items coded 5 were calibrated as being full members of the target set (i.e., 0.951), items coded 3 were calibrated as being neither in nor out of the target set (i.e., 0.501) and items coded 1 were calibrated as being full non-members of the target set (i.e., 0.051). By virtue of the calibration process, we stipulated the degree to which each case has membership in the set of cases having a certain property (Ibid). For example, when calibrated, ease of interaction represents the degree to which each $\mathrm{B} 2 \mathrm{~B}$ SME belongs to the set of B2B SMEs whose staff find social media easy to interact with. Nevertheless, we performed several robustness tests by setting different anchor points for full membership and full non-membership in the target set (see the Appendix).

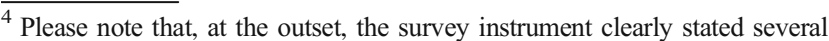
examples of the outcome of interest (our research aim) such as changing governance arrangements swiftly in the context of new terms of service, changing privacy settings promptly in the context of new privacy policies, changing security policies rapidly, etc. Furthermore, "like other methodologies the QCA approach serves to provide empirical evidence that may or may not support causal inferences based in theory" (Greckhamer et al. 2008: 724; footnote 1). In other words, "inferences about causal relationships are based in theory" (Ibid) despite QCA terminology about causation and causality (e.g., explanatory/causal conditions, outcome of interest, etc.).
}

Step 2: Determining the Outcome Value for each Truth-Table Row In the second step, the outcome value for each truth-table row was determined based on the minimum number of cases required for a solution, that is, a statement about one or multiple combinations of conditions joined by logical AND $(*)$. When the total number of cases included in the analysis is medium (e.g., between 10 and 100 cases), researchers can opt for just one case as their minimum threshold (Goertz and Mahoney 2012; Schneider and Wagemann 2012). That is, just one case with a certain combination of variables and a given outcome is sufficient to establish the existence (or not) of a causal "recipe" that links a causal configuration to the outcome of interest. Of course, with larger numbers of cases this limit can be set higher. Therefore, in this paper we set a frequency threshold of 1 to discriminate between remainders and non-remainders, the former being empty rows, the latter being rows populated with empirically-strong cases. However, we also ran several robustness tests with higher frequency thresholds (e.g., 3 or 5 cases) to validate our results (see the Appendix).

We then considered the consistency (sufficiency) level for each row populated with cases. Consistency (sufficiency) is a measure that gauges the degree to which a causal condition or combination of conditions is a subset of the outcome. Since researchers must set consistency thresholds for sufficiency not below 0.75 (Ragin 2008), we set our consistency sufficiency threshold for adaptive acceptance at 0.79 to avoid untenable assumptions that contradicted our expectations. Accordingly, truth-table rows with consistency above 0.79 were given a score of 1 since the configuration was roughly a consistent subset of the outcome, or 0 if not. The empty rows in the truth table were labeled "remainders" (or potential counterfactuals) because they did not meet our minimum numberof-cases threshold.

Step 3: Minimizing the Truth Table In the final step, we used the fsQCA program to minimize the truth table and derive more parsimonious (i.e., shorter or less complex) solutions in a theoretically-guided manner. Based on "what if" claims about the remainders (Durand and Vaara 2009), we formulated conjunctural directional expectations about the universe of empty rows in the following fashion. First, we set a consistency necessity threshold of 0.90 or above (Schneider and Wagemann 2012) to identify conditions that were roughlyconsistent supersets of the outcome of interest. Next, we barred from the minimization process those remainders that contradicted at least one necessary condition (Ibid). Thus, we postulated that the absence of just one necessary condition must warrant the absence of the outcome of interest (i.e., non-adaptive/routinized acceptance). We then coupled the necessary conditions for adaptive acceptance with the complements of the necessary conditions for negative cases (and 
Table 1 Survey items used for the determinants of Adaptive Acceptance with sources

Perceived Usefulness

(Post-adoption

perceptions of usefulness) ${ }^{\text {a }}$

Perceived Ease

of Use

(Post-adoption perceptions of effortlessness) ${ }^{\text {a }}$
We (i.e., the SME) find social media useful in enhancing our business performance (Adapted from Gefen and Straub 2000)

Social media attract new customers to the company (Adapted from Michaelidou et al. 2011) Social media have helped the company raise its profile (Adapted from Michaelidou et al. 2011)

Learning to use social media is easy for us (Adapted from Gefen and Straub 2000)

Staff have become skillful at using social media (Adapted from Gefen and Straub 2000)

Staff find social media easy to interact with (Adapted from Gefen and Straub 2000)

${ }^{\text {a }}$ List of conditions individually necessary and jointly sufficient for concept formation (Scale from $1=$ strongly disagree to $5=$ strongly agree). As well as theoretical sources (e.g., Gefen and Straub 2000; Michaelidou et al. 2011; etc.), the survey items drew from prior expert interviews held with Alpha's Managing Director

vice versa) to formulate conjunctural directional expectations on sufficient conjunctions of conditions (Ibid). ${ }^{5}$

\subsection{The Data Collection Methods}

Data were collected using both quantitative (i.e., a survey) and qualitative (i.e., interviews and email exchanges) methods. We used a short web-based exploratory survey (Sue and Ritter 2012) to gather information from SMEs that were geographically dispersed in the South East of England. Since the focus of our study was B2B SMEs, we used an online questionnaire to contact 102 SMEs based on Alpha's customer database. These 102 SMEs were contacted using several social media tools (e.g., LinkedIn, Twitter, etc.) to ensure that they were real social media adopters/users regardless of respondents' age (Cf. Siamagka et al. 2015: 93). Out of the 102 SMEs that participated in the survey, 20 companies were removed either because of conflicting data (i.e., negatively-worded items did not match positively-worded items when reverse coded) or because they were primarily engaged in $\mathrm{B} 2 \mathrm{C}$ activities.

Exploratory research is conducted during the early stages of research when the core objective is to gain preliminary insights on a topic (Forza 2002). Being exploratory, the survey was kept relatively short (Åhlström and Westbrook 1999). Most items asked respondents to rate issues surrounding the use of social media. Such issues included the usefulness and ease of use of social media in general and the usefulness of specific social media platforms in particular (e.g., Blogs, Twitter, LinkedIn, etc.), as well as the methods used to measure the effectiveness of social media (e.g., Google Analytics, Page Views, etc.). The survey also included a section on sector of operation, annual turnover, number of employees and number of years the SME in question was in business. Validated

\footnotetext{
$\overline{{ }^{5} \text { Formally, if } \mathrm{x}} \leftarrow \mathrm{y}$ and $\sim \mathrm{z} \leftarrow \sim \mathrm{y}$, THEN $\mathrm{x} * \mathrm{z} \rightarrow \mathrm{y}$ where: $\leftarrow$ indicates necessity; $\rightarrow$ indicates sufficiency and $*$ indicates conjunction (AND). Thus, if $\mathrm{x}$ is necessary for $\mathrm{y}$ and the directional expectation that follows from the empirical finding that $\sim \mathrm{z}$ is necessary for $\sim \mathrm{y}$ is that $\mathrm{z}$ is sufficient for $\mathrm{y}$ (Cf. Schneider and Wagemann 2012: 206, footnote 10), then it is logical to expect the conjunction of $\mathrm{x}$ AND $\mathrm{z}$ to lead to $\mathrm{y}$ regardless of whether $\mathrm{x}$ is a single condition or a configuration of causal conditions. As well as logically and empirically, our assumptions were theoretically driven (Cf. Michaelidou et al. 2011; Siamagka et al. 2015; etc.).
}

instruments and preliminary meetings with Alpha's Managing Director informed all survey items. The choice of rating scales was justified by the exploratory character of our research. Rating scales are easy to understand and, therefore, suitable for online surveys (Sue and Ritter 2012).

The survey instrument was administered by Alpha and was trialed for 1 week in January 2012 to gather feedback and reduce potential biases, as well as ensure the wording was fully understandable. Survey items were randomized to reduce the impact of common methods bias on the true scores (Straub et al. 2004) and some items were both positively and negatively worded to check respondents' answers. Data were collected on Survey Monkey during the last 2 weeks of February 2012. Given the strategic nature of technology adoption, the small size of the companies in question, current data collection methods in the context of SMEs (Li et al. 2011), and considering that group membership is more ingrained in SMEs' owners than their employees (Haugh and McKee 2004), we chose a single respondent per SME, usually the Founder and/or Managing Director. All respondents were promised a summary of results to be emailed back to them upon request, as well as participation in a prize draw.

Qualitative data were gathered using unstructured and semi-structured interviews with Alpha's Managing Director and twenty-four, follow-up email exchanges with Alpha's B2B customers to triangulate our data sources and assess the internal validity of our causal model. We held a total of three interviews with Alpha's Managing Director. Each interview lasted approximately $90 \mathrm{~min}$. Two interviews took place before the administration of the survey instrument in a very unstructured and exploratory fashion. The third interview occurred afterwards to discuss our findings and their practical implications. Multiple interviewers participated in each round of interviews to probe several lines of inquiry and cross-check our findings. The Alpha Managing Director was purposefully selected for the interviews because she is a social media expert. As such, the interviews followed the expert interview protocol (Flick 2009) to complement the survey method and help us develop the survey instrument at first and subsequently validate our findings in a more nuanced and structured fashion. All interviews were digitally recorded and analyzed by searching for broad themes (Braun and Clarke 2006). 
Several themes emerged from the analysis of interview transcripts but only a few were examined more deeply through follow-up email exchanges with Alpha's B2B customers.

\section{Findings}

Once converted into fuzzy sets, we analyzed the data with the truth-table approach using the fsQCA 2.5 program (Ragin and Davey 2014). Though the truth table is the predominant mode of sufficiency analysis in QCA, we first performed an analysis of necessity with the "necessary conditions" procedure by setting a consistency (necessity) threshold of 0.96 for positive cases to avoid considering ease of learning as being both necessary and sufficient for adaptive acceptance. ${ }^{6}$ This produced the following necessary conditions (see conditions highlighted in bold in Table 2).

Subsequently, we created a dichotomous truth table from our calibrated data. Thus, we obtained a truth table with $2^{6}$ rows (i.e., 64 rows) where each row denotes a logicallypossible configuration of conditions. Table 3 shows the truth table for positive cases.

Each row of Table 3 represents a configuration of 6 causal conditions where $1 \mathrm{~s}$ and $0 \mathrm{~s}$ stand for full membership and full non-membership in each condition respectively. For example, the first row of the truth table represents a configuration of 6 causal conditions that are all present. The third row, instead, indicates a configuration of 6 causal conditions where only enhancing business performance, attracting new customers, and raising the company's profile are present, thus pointing to a straightforward pattern or commonality across the top three rows. For each row, the number of cases that uniquely travel along that causal configuration is indicated (see the column "Number") with each case having a membership greater than 0.5 for that particular configuration. The truth table also indicates the raw consistency of each row (i.e., the consistency of each truth-table row with the statement of sufficiency, namely that the row in question is a subset of the outcome). The Proportional Reduction in Inconsistency (PRI) score, instead, "is a more refined and conservative measure of consistency" that helps moving from not knowing if the causal condition is a

\footnotetext{
6 IF $\sim$ fsEase_Learning $\leftarrow \sim$ fsAdaptive_Accept THEN fsEase_Learning $\rightarrow$ fsAdaptive_Accept (see the Appendix). Hence, setting a consistency necessity threshold of 0.95 would imply that fsEase_Learning $\leftrightarrow$ fsAdaptive_Accept, that is, ease of learning is necessary and sufficient for adaptive acceptance. This is a very restrictive assumption that can be avoided by "drawing only a limited amount of inferences" from our truth table (Cf. Schneider and Wagemann 2016: 320). To put it another way, by setting a consistency necessity threshold of 0.96 we restrict the number of causal conditions that are theoretically and empirically "meaningful" supersets of the outcome (Cf. Schneider 2019: 1115). There is no way B2B SMEs will adapt to complex social media policy changes if their business model revolves around face-toface interactions even if they find social media easy to learn. They will deliberately non-adapt to complex social media policy changes because social media do not help attract new customers and raise their company's profile.
}

Table 2 Analysis of necessary conditions ( $\sim$ indicates absence of the condition in question. Consistency necessity set at 0.96 . Necessary conditions in bold; Outcome variable: fsAdaptive_Accept)

\begin{tabular}{lll}
\hline Conditions tested & Consistency & Coverage \\
\hline fsPerformance & 0.94 & 0.91 \\
fssPerformance & 0.28 & 0.70 \\
fsCustomer_Attr & $\mathbf{0 . 9 9}$ & 0.93 \\
$\sim$ fsCustomer_Attr & 0.23 & 0.62 \\
fsCompany_Profile & $\mathbf{1 . 0 0}$ & 0.86 \\
$\sim$ fsCompany_Profile & 0.19 & 0.71 \\
fsEase_Learning & 0.95 & 1 \\
$\sim$ fsEase_Learning & 0.27 & 0.56 \\
fsSkillfulness & 0.90 & 0.98 \\
$\sim$ fsSkillfulness & 0.32 & 0.62 \\
fsEase_Interact & 0.93 & 0.98 \\
$\sim$ fsEase_Interact & 0.29 & 0.61 \\
\hline
\end{tabular}

fsPerformance $=$ Fuzzy-Set of B2B SMEs enhancing Business Performance; fsCustomer_Attr $=$ Fuzzy-Set of B2B SMEs Attracting new Customers; fsCompany_Profile: Fuzzy-Set of B2B SMEs raising the Company's Profile; fsEase_Learning = Fuzzy-Set of B2B SMEs finding social media Easy to Learn; fsSkillful = Fuzzy-Set of B2B SMEs becoming Skillful at using social media; fsEase_Interact = Fuzzy-Set of B2B SMEs finding social media Easy to Interact with; fsAdaptive Accept $=$ Fuzzy-Set of B2B SMEs Accepting and Adapting to social media policy change quickly

subset of the outcome or the absence of the outcome to asserting that it is a subset of the presence of the outcome (Mendel and Ragin 2011: 38). Lastly, Symmetry Consistency (SYM Cons) is a tweaked version of PRI Consistency that was developed for fuzzy-set analyses where one wants to study both positive and negative cases (Ragin 2015).

Given our frequency threshold of 1 case (see Step 2 above), we declared as remainders those rows containing no cases at all. Subsequently, we deployed the TheoryEnhanced Standard Analysis (TESA) as follows. We first barred from the minimization process those remainders that contradicted the statement of necessity (i.e., those configurations where at least one necessary condition was absent). This was done by coding such remainders with an outcome value set at 0 . We then formulated conjunctural directional expectations with regard to the remaining empty rows as follows. We conjectured that the simultaneous presence of the two necessary conditions for adaptive acceptance (i.e., customer attraction and company profile) coupled with the complement of at least one necessary condition for routinized acceptance (i.e., ease of learning, skillfulness, or ease of interaction see the Appendix) should lead to adaptive acceptance of social media policy changes. We further conjectured that the simultaneous presence of the two necessary conditions for adaptive acceptance coupled with the presence of an enhanced business performance should too lead to adaptive acceptance because this conjecture makes theoretical sense (Michaelidou et al. 
Table 3 Truth table for positive cases (with no set membership in the outcome and no remainders or empty rows)

\begin{tabular}{|c|c|c|c|c|c|c|c|c|c|}
\hline fsPerform & fsCust_Attr & fsComp_Profile & fsEase_Learn & fsSkillfulness & fsEase_Interact & Number fsAdaptive_Accept & $\begin{array}{l}\text { Raw } \\
\text { Cons }^{\text {a }}\end{array}$ & $\begin{array}{l}\text { PRI } \\
\text { Cons }\end{array}$ & $\begin{array}{l}\text { SYM } \\
\text { Cons }\end{array}$ \\
\hline 1 & 1 & 1 & 1 & 1 & 1 & $\begin{array}{l}64 \\
(78 \%)\end{array}$ & 1.00 & 1.00 & 1.00 \\
\hline 1 & 1 & 1 & 0 & 1 & 1 & $4(83 \%)$ & 0.92 & 0.68 & 0.68 \\
\hline 1 & 1 & 1 & 0 & 0 & 0 & $8(93 \%)$ & 0.79 & 0.40 & 0.40 \\
\hline 1 & 0 & 1 & 0 & 0 & 0 & $3(96 \%)$ & 0.72 & 0.09 & 0.09 \\
\hline 0 & 0 & 1 & 0 & 0 & 0 & $1(98 \%)$ & 0.71 & 0.09 & 0.09 \\
\hline 0 & 0 & 0 & 0 & 0 & 0 & $2(100 \%)$ & 0.71 & 0.00 & 0.00 \\
\hline
\end{tabular}

Please note that, due to limitations of space, only 6 out of the 64 possible configurations are described because they have empirical instances.

fsPerformance $=$ Fuzzy-Set of B2B SMEs enhancing Business Performance; fsCustomer_Attr = Fuzzy-Set of B2B SMEs Attracting new Customers; fsCompany_Profile: Fuzzy-Set of B2B SMEs raising the Company's Profile; fsEase_Learning = Fuzzy-Set of B2B SMEs finding social media Easy to Learn; fsSkillful = Fuzzy-Set of B2B SMEs becoming Skillful at using social media; fsEase_Interact = Fuzzy-Set of B2B SMEs finding social media Easy to Interact with; fsAdaptive_Accept $=$ Fuzzy-Set of B2B SMEs Accepting and Adapting to social media policy change quickly

${ }^{\mathrm{a}}=$ Consistency of a single truth-table row with the statement of sufficiency (that is, whether the combination of causal conditions is a subset of the outcome)

${ }^{\mathrm{b}}=$ Proportional Reduction in Inconsistency (an additional parameter to interpret set-theoretic relations)

${ }^{\mathrm{c}}=$ Symmetry Consistency (a tweaked version of PRI Consistency)

2011; Paluch et al. 2015). All non-remainders were subsequently coded 1 in the outcome variable "fsAdaptive_Acceptance" if they met our consistency thresholds for sufficiency (i.e., 0.79) or 0 otherwise. Our solutions are reported in Table 4.

Ultimately, Table 4 shows that there are two empirically non-redundant pathways to adaptive acceptance, namely, the enhancing business performance and the ease of learning pathways with a non-zero unique coverage. Furthermore, the analysis of the negative cases (see the Appendix) confirms the relevance of ease of learning. Indeed, the lack of ease of learning is the most relevant pre-requisite for routinized acceptance

Table 4 Theory Enhanced Standard Analysis (TESA) for positive cases (Black circles indicate the presence of a condition. Large circles indicate necessary conditions; small ones, contingent conditions. Blank spaces (see the Appendix). These findings are further analyzed below where we probe whether ease of learning (or the lack thereof) can explain contrasting results in terms of adaptive vs. nonadaptive/routinized acceptance.

\section{Analysis of Findings from Cross-Case Comparisons}

In relation to the two-fold research question (RQ) set out in the Introduction (Section 1), our findings reveal that there are multiple, partially-overlapping pathways to B2B SMEs' indicate 'don't care', that is, situations where causal conditions may be either present or absent) $)^{\dagger}$

$\begin{array}{ll}\text { Solutions (S) }{ }^{\dagger \dagger} & \\ \text { fscustomer_attr } \\ \text { fscompany_profile } \\ \text { fsperformance } \\ \text { fsease_learning } \\ \text { fsskillfulness } \\ \text { fsease_interact }\end{array}$

$\dagger$ Legend: fscustomer_attr= Fuzzy-Set of B2B SMEs Attracting new Customers; fscompany_profile= Fuzzy-Set of B2B SMEs raising the Company's Profile; fsperformance= Fuzzy-Set of B2B SMEs enhancing Business Performance; fsEase_Learning= Fuzzy-Set of B2B SMEs finding social media Easy to Learn; fsskillfulness= Fuzzy-Set of B2B SMEs becoming Skillful at using social media; fsEase_Interact= Fuzzy-Set of B2B SMEs finding social media Easy to Interact with

$\dagger \dagger$ Solutions are statements about one or multiple combinations of conditions joined by logical AND $(*)$ 
adaptive acceptance of social media policy changes (see Table 4). Within these pathways, two main causal recipes stand out which instantiate two overall types of configurations, namely pure configurations of usefulness (i.e., causal recipes using only "usefulness" ingredients which are contingent on an enhanced business performance) and hybrid configurations (i.e., causal recipes mixing both "usefulness" and "ease-of-use" ingredients which are contingent on ease of learning). Though all pathways feature high consistency scores, it is worth stressing that consistency (sufficiency) is a gauge of theoretical importance (Rivard and Lapointe 2012). To identify the most important empirical pathway one instead needs to look at the coverage scores (Ragin 2008). Coverage (sufficiency), in particular, refers to how much of the membership of the outcome is covered by the path either singularly (i.e., unique coverage) or in combination with other paths (i.e., raw coverage). Since the ease of learning path has the highest scores in terms of raw and unique coverage ( 0.95 and 0.009 respectively) and since this path is replicated across 64 SMEs that are neither contradictory nor inconsistent with the outcome (Schneider and Wagemann 2012), it follows that this pathway is the most important route to the outcome of interest both theoretically and empirically. The partitioning of the pathways to the outcome of interest can be depicted with a Venn diagram displaying, for reasons of simplicity, only empirically non-redundant pathways with a non-zero unique coverage (i.e., the "ease of learning" and "enhancing business performance" pathways). The Venn diagram below illustrates these findings (see Fig. 8).

Therefore, in the relatively-small sample of B2B SMEs at our disposal, the most important pathway is the one entailing a conjunction among three factors, namely attracting new customers, raising the company's profile, and learning to use social media effortlessly (i.e., the complement of non-ease of learning). Indeed, the analysis of the negative cases corroborates these findings because it shows that the lack of ease of learning is the most relevant necessary condition for routinized acceptance (see the Appendix). Why is the ease-oflearning pathway the most important route to B2B SMEs' adaptive acceptance of social media policy changes?

Attracting new customers and raising the company's profile create a cognitive strain on B2B SMEs because they require constant feeding of information on social media (Siamagka et al. 2015). As reported by an informant:
Social media demand constant monitoring and once you have engaged in dialogue, it is impossible to withdraw (Managing Director, B2B SME \#19)

Other informants reiterated this point:

Finding inexpensive means of attracting new clients and promoting ourselves in a quick manner is tricky on social media. Most of it is very time consuming (Managing Director, B2B SME \#7)

Furthermore, external disturbances such as new features or applications can affect the consequences of the use of social media because they can make it harder to learn how to use social media (see Fig. 2). Our informants corroborate these insights:

We found social media easy to learn initially, though there is a lot more to them than you first realize and to be honest in order to make them work properly for any small business they would need to spend a lot of time keeping up to speed with the new changes and also learning about all the options they have for each platform (Managing Director, B2B SME \#10)

It was easy a few years back. The tools (LinkedIn, Twitter, and Facebook) were fairly straightforward and uncomplicated. That has since changed and unless you are using social media on a very regular basis then there always seems to be some new featurelfunction to come to terms with; it's understandable, but timeconsuming if you are managing any page or group and it's not your full-time or even part-time job (Managing Director, B2B SME \#17)

Considering that the skillfulness and ease of interaction pathways are empirically redundant (see Table 4), our findings show that the easier B2B SMEs find learning to use social media, the more skillful they become at using new features and at interacting with social media. This, in turn, will make it easier to cope with the effort associated with a more thoughtful use of social media geared toward attracting new customers and raising the company's profile (Siamagka et al. 2015). Accordingly, ease of learning counteracts the cognitive effort required to attract new customers and raise the
Fig. 8 Venn diagram partitioning of empirically non-redundant pathways to adaptive acceptance of social media policy changes (most important path represented by a dash circle)

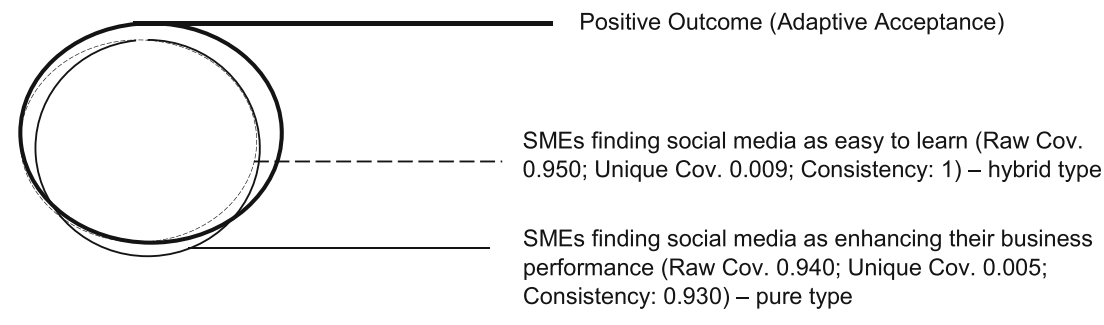


company's profile, thus making cognitive energy available to accept (make sense of) and adapt (respond) to complex policy changes quickly.

There is more to this recipe for adaptive acceptance than meets the eye. Social media are dynamic technologies that are in a constant state of flux (Hogan and Quan-Haase 2010). Not only are new social media tools developed at a rapid pace, but existing platforms and technologies are constantly being updated with new "features, policies, and applications" (Ibid: 309) that may disrupt existing practices. While new features and/or applications may signal a surface change to existing procedures, new social media policies may mark a more radical departure from existing business practices because they may entail developing new governance arrangements within organizations (Vaast and Kaganer 2013). Put differently, compared with user interface changes, new social media policies may call for a more concerted approach to cope with and respond to change swiftly.

For example, when Facebook launched its new interface in September 2011, users were given a 7-day grace period to remove, hide, or customize the visibility of old posts before they went live on Timeline. ${ }^{7}$ No concerted strategy was required to cope with these changes. On the contrary, when Facebook changed its privacy policy in August 2011, businesses realized that there are risks associated with social media that make it imperative to coordinate response efforts. Since social media policies set out the rules of the game, it is likely that policy changes will affect both the visibility of information posted on social media, as well as its persistence and durability over time (Vaast and Kaganer 2013). As remarked by our informants:

Facebook has changed privacy policy and Instagram has recently issued new terms and conditions (e.g., about ownership of photos). There are risks associated with social media because they can entail losing control over sensitive information disclosed in the public domain... Social media are not just about Marketing and PR [Public Relations]. Legal teams too have to be involved because of the implications of protecting the brand. The whole organization must develop governance principles that set out the rules for the disclosure of sensitive information, as well as what not to post on social [media] (Managing Director, Alpha)

Likewise, other informants stressed the need for a mindful use of social media to minimize the risks associated with the disclosure of sensitive information (Chen and Sharma 2013; Richey et al. 2018). Since sharing is a core principle of most

\footnotetext{
${ }_{7}$ Source: https://newsroom.fb.com/news/2011/09/tell-your-story-withtimeline/ Accessed 22 November, 2017.
}

social media platforms, others can see, copy, and use that information for their own purposes:

The use of social media can make business interactions and operations more transparent. Public sharing of 'connections' allows similar companies to identify customers who they may not otherwise have had the knowledge of / means of contacting (Managing Director, B2B SME number \#3)

Incautious use of PR [Public Relations] on social media channels potentially threatens to disclose key customer relationships, key business advantages or commercially sensitive information to competitors (Managing Director, B2B SME number \#5)

We have to be mindful of platforms like LinkedIn, where other competitors could see our customers if our clientfacing staff have them as connections. We make sure our staff are aware of this (Managing Director, B2B SME number \#23)

In a nutshell, the main risk is lack of control. All staff can become spokespeople for the business. All staff are communicating (publicly in many cases) information for and about the business. If businesses are not clear in briefing their staff and representatives on what is and isn't appropriate they open themselves up to huge risks in the information that could, often innocently but naively, be shared (Managing Director, B2B SME \#20)

Indeed, Twitter, LinkedIn, Google and Facebook have updated their policies on a regular basis (Fuchs 2014). Not only have these companies made numerous updates. They have also increased the complexity and length of these policies to such an extent that it is unlikely that users (including B2B SMEs) will read them in detail (Ibid). As remarked by a B2B SME Director:

Social media are not user friendly. They are too complicated because they are always changing. It is impossible to learn how to get around problems because they are very time consuming. There are unexpected policy and rule changes that may undermine control over sensitive information. You are expected to have a high-level understanding of social media (Managing Director, B2B SME \#11)

Not only are these policy changes very complex for any small business. They also entail more adaptive strategies aimed at changing governance arrangements swiftly and modifying security policies rapidly to respond in a timely fashion. As remarked by our informants:

If your social media content is out there in the social media sphere, it means anyone can get hold of it and 
share it. You should nominate a certain number of colleagues to be social media advocates / representatives for your organization, and make sure there is a consistent tone / message / personality with postings to your organizations' social media channels. All colleagues should also be guided in how to use social media to positive effect for their own personal use - remember, we are always representatives to the organizations that we work for (Managing Director, B2B SME number \#4) To ensure we mitigate any potential threats to the organization or its customers we have a closely-monitored social media policy. We ensure that we send out preagreed and coordinated messages. Those sites where we engage in conversation, this is done under guidelines and by nominated members of staff (Managing Director, B2B SME \#5)

Ultimately, learning to use social media effortlessly can free cognitive energy for making sense of and responding to complex policy changes, thus leading to a more mindful (or adaptive) use of social media.

\section{Discussion and Conclusion}

In this study, we have endeavored to identify a plausible range of causal factors that can lead to the adaptive acceptance of social media on the assumption that adaptive acceptance is a cognitive and behavioral process that consists of promptly accepting (making sense of) and adapting (responding) to social media policy changes quickly. In our quest for the causal configurations leading to the occurrence of the outcome of interest, we have discovered that the ease-of-learning recipe is the most important pathway both theoretically and empirically. Since social media are embedded within larger ecologies (Kallinikos et al. 2013; Kane et al. 2014), they are constantly shifting (Schlagwein and Hu 2017; Wisniewski et al. 2014), thus triggering a process of continuous adaptation which can challenge routinized procedures, competences, and capabilities. As attention is neither limitless nor free, some changes will be heeded while others inevitably will be not. As a consequence, an attention deferral mechanism may be triggered which may entail sacrificing early comprehension of complex social media policy changes. In addition, routinized procedures based on more traditional networking and off-line interactions may narrow attention in a way that reduces acuity for changing circumstances (Swanson and Ramiller 2004). Accordingly, B2B SMEs may become trapped in their routinized procedures, competences, and capabilities and may find it hard to learn how to switch cognitive gears from automatic (or mindless) to more active (or mindful) thinking modes (Sun 2012). Thus, B2B SMEs' owners/managers need to counteract these negative dynamics by enacting disturbance-handling strategies (Beaudry and Pinsonneault 2005). They also need to create fluid organizational structures that incorporate ongoing learning in the form of frequent training programs, periodical reviews, and institutionalized playfulness.

\subsection{Theoretical, Practical, and Methodological Implications}

Our study has theoretical, practical, and methodological implications for social media researchers and B2B SMEs.

\subsubsection{Theoretical Implications}

Theoretically, though TAM and its revisions (Dwivedi et al. 2019) are less widely utilized in the domain of social media (Kapoor et al. 2018), this paper draws on past technologyacceptance research to develop the concept of adaptive acceptance. Adaptive acceptance is very similar to the concept of enterprise agility (Nazir and Pinsonneault 2012; Overby et al. 2006; Zhao et al. 2007) or organizational agility (Park et al. 2017; Trinh-Phuong et al. 2012) recently introduced in the IS literature. Both adaptive acceptance and agility apply to "episodic events precipitated by environmental change" (Overby et al. 2006: 122). Nevertheless, a few conceptual and methodological nuances set adaptive acceptance apart from enterprise or organizational agility.

Firstly, as the conceptual outcome of interest, adaptive acceptance deals with specific (environmental) change drivers (e.g., social media policy changes) rather than a wider range of (environmental) change drivers. Secondly, adaptive acceptance deals with reactive change rather than capturing both proactive and reactive change (Overby et al. 2006). Thirdly, from a methodological perspective, adaptive acceptance draws on "the concept PLUS attributes" approach (Beach and Pedersen 2016: 106-108) rather than measuring sensing and responding capabilities separately and then using specific techniques for aggregating individual scores (Overby et al. 2006). Accordingly, adaptive acceptance has different causal properties when compared with non-adaptive/routinized acceptance, thus warranting the theorization of different subtypes of the concept of acceptance (see Fig. 1). In other words, the configurations leading to adaptive acceptance are not simply the reverse of the configurations for non-adaptive/routinized acceptance (see Table 4 and the Appendix).

Furthermore, using the "concept PLUS attribute" approach entails that the number of cases included in a concept definition (extension) decreases as the number of attributes in a concept increases (intension) (Beach and Pedersen 2016: 107; their italics). This, in turn, enables scholars to look for additional attributes of adaptive acceptance to arrive at a more nuanced definition of this concept that refines the notion of mindfulness. Ultimately, a comprehensive and comparative analysis between mindfulness and mindlessness as a 
continuum (i.e., mutually exclusive) or, alternatively, as opposite poles is missing in information systems research (Dernbecher and Beck 2017). Not only does this paper fill this literature gap. It also provides new insights on the mindfulness-mindlessness antonym revolving around the idea that "using the same (cognitive) resources implies mutual exclusivity" (Ibid: 137).

\subsubsection{Practical Implications}

Implications for practice suggest that B2B SMEs' owners/ managers should level the playing field between issues of cost efficiency and issues of innovation by pursuing simultaneously stability, efficiency, and exploitation in tandem with flexibility, innovation, and exploration (Huang et al. 2013; March 1991). For instance, depending on the culture and size of the B2B SME in question, a select few members of staff should undertake fluid "boundary-spanning" roles aimed at brokering new connections with unknown businesses, building larger networks of heterogeneous contacts, managing and converting new leads. Similarly, playfulness and trial-anderror learning should be encouraged by enabling staff to bring their own devices at work and using them responsibly (Leclercq-Vandelannoitte 2015).

Alongside these exploration-oriented activities, B2B SMEs' owners/managers should help their staff to cope with social media policy changes more mindfully. For instance, they should deploy additional tools (e.g., filtering tools, social media text miners, etc.), programs (i.e., formal training programs, formal review meetings, etc.), and policies (i.e., governance rules, guidelines, etc.) that make the use of social media more efficient, deliberate, and codified.

\subsubsection{Methodological Implications}

As well as theoretical and practical implications, this paper has methodological implications because it responds to calls for new methodologies in the study of social media (Agarwal and Dhar 2014; Kallinikos et al. 2013; Merali et al. 2012; Whelan et al. 2013). Very recently, IS adoption models in general and TAM models in particular have been criticized for being unable to capture more complex interaction effects in an asymmetric fashion (Liu et al. 2017). This paper shows that QCA is able to tweak the variance-oriented underpinnings of TAM research in a systems-oriented (or configurational) way (El Sawy et al. 2010; Henfridsson and Bygstad 2013; Park et al. 2017). Hence, one can capture the pathways leading to adaptive acceptance by carefully pinpointing several configurations of causal conditions. Each pathway can be conceptually related to a causal configuration or "recipe" where causal conditions can interact with each other at a higher or lower-level of analysis (Iannacci and Cornford 2018).
Such configurations, in addition, can incorporate causal mechanisms that complement each other in some contexts or counteract one another in other contexts (Ibid). Specifically, ease of learning can counteract the cognitive effort associated with attracting new customers and raising the company's profile, thus freeing cognitive energy for coping with complex policy changes more mindfully (or adaptively). Ultimately, ease of learning is the primary engine toward mindfulness, that is, the primary pathway toward reactive and nonautomated decisions.

\subsection{Limitations and Future Research Directions}

This research suffers from five limitations. First, the use of purposive sampling can bias the (statistical) generalizability of our findings. Hence, one should draw analytical rather than statistical generalizations from our research (Yin 2014). For example, generalizations that extend the relevance of ease of learning beyond the initial stages of adoption. Another analytical generalization relates to the fact that B2B SMEs that learn to use social media effortlessly have developed a dynamic capability that enables them to switch cognitive gears from habitual to more active thinking modes (Sun 2012). This, in turn, helps them to enact disturbance-handling strategies (Beaudry and Pinsonneault 2005) to cope with ongoing changes in terms of new social media policies. Short of this dynamic capability, B2B SMEs are bound to become unresponsive to radical social media policy changes and eventually turn into passive users that adopt social media without using them (see Fig. 2).

Second, considering that TAM (and its derivatives) is an individual-level theory, our findings apply primarily to smallish B2B SMEs with fewer than 100 staff ( $\mathrm{Li}$ et al. 2011). Hence, if one were to draw statistical generalizations from our purposive sample (admittedly a research aim we did not intend to pursue in this paper), we recommend generalizing our findings to populations of B2B SMEs with fewer than 100 staff rather than all B2B SMEs regardless of their size. Third, the model developed in the paper overlooks the role of thirdparty vendors (e.g., Hootsuite, Union Metrics, etc.). Arguably, these vendors develop complementary features that add a layer of complexity because they are subjected to their own policies. Future research may wish to investigate how B2B SMEs cope with changes from third-party vendors' policies beyond social media platforms policy changes. Fourth, the use of selfreported measures can bias our findings. Hence, future research could look at more objective metrics of actual behaviors (e.g., indicators measuring the number, timeliness, and frequency of new accepted policies, new business practices formally approved, etc.). Fifth, and last, our results should not be interpreted as proof of causal relationships because of the exploratory and cross-sectional nature of our research design. Nevertheless, they lend support for the existence of 
causal mechanisms (e.g., counteracting and self-reinforcing mechanisms) that may be aptly pinpointed through processtracing techniques and longitudinal case studies.

Acknowledgments Many thanks to the e-Government and e-Business Group within the British Academy of Management for their comments on early drafts of this paper. Special thanks go to Katie King and Zoodikers for helping us with data collection. All errors of fact or logic are the sole responsibility of the authors.

Open Access This article is licensed under a Creative Commons Attribution 4.0 International License, which permits use, sharing, adaptation, distribution and reproduction in any medium or format, as long as you give appropriate credit to the original author(s) and the source, provide a link to the Creative Commons licence, and indicate if changes were made. The images or other third party material in this article are included in the article's Creative Commons licence, unless indicated otherwise in a credit line to the material. If material is not included in the article's Creative Commons licence and your intended use is not permitted by statutory regulation or exceeds the permitted use, you will need to obtain permission directly from the copyright holder. To view a copy of this licence, visit http://creativecommons.org/licenses/by/4.0/.

\section{References}

Agarwal, R., \& Dhar, V. (2014). Editorial - Big data, data science, and analytics: the opportunity and challenge for IS research. Information Systems Research, 25(3), 443-448.

Åhlström, P., \& Westbrook, R. (1999). Implications of mass customization for operations management: an exploratory survey. International Journal of Operations \& Production Management, 19(3), 262-275.

Ajzen, I., \& Fishbein, M. (2000). Understanding attitudes and predicting social behavior. London: Prentice-Hall International Ltd..

Aral, S., Dellarocas, C., \& Godes, D. (2013). Social media and business transformation: a framework for research. information systems Research, 24(1), 3-13.

Bagozzi, R. P. (2000). On the concept of intentional social action in consumer behavior. Journal of Consumer Research, 27(3), 388396.

Beach, D., \& Pedersen, R. B. (2016). Causal case study methods: Foundations and guidelines for comparing, matching, and tracing. Ann Arbor: University of Michigan Press.

Beaudry, A., \& Pinsonneault, A. (2005). Understanding user responses to information technology: a coping model of user adaptation. MIS Quarterly, 29(3), 493-524.

Bell, J., \& Loane, S. (2010). New-wave global firms: Web 2.0 and SME internationalization. Journal of Marketing Management, 26(3-4), 213-229.

Berg-Schlosser, D., De Meur, G., Rihoux, B., \& Ragin, C. (2009). Qualitative comparative Analysis (QCA) as an approach. In B. Rihoux \& C. Ragin (Eds.), Configurational comparative methods: Qualitative comparative analysis (QCA) and related techniques (pp. 1-18). London: Sage Publications.

Bharati, P., Zhang, C., \& Chaudhury, A. (2014). Social media assimilation in firms: investigating the roles of absorptive capacity and institutional pressures. Information Systems Frontiers, 16(2), 257272.

Braun, V., \& Clarke, V. (2006). Using thematic analysis in psychology. Qualitative Research in Psychology, 3(2), 77-101.
Burton-Jones, A., \& Grange, C. (2013). From use to effective use: A representation theory perspective. Information Systems Research, 24(3), 632-658.

Carlo, J. L., Lyytinen, K., \& Boland Jr., R. J. (2012). Dialectics of collective minding: contradictory appropriations of information technology in a high-risk project. MIS Quarterly, 36(4), 1081-1108.

Chen, R., \& Sharma, S. K. (2013). Self-disclosure at social networking sites: an exploration through relational capitals. Information Systems Frontiers, 15(2), 269-278.

Chiu, D. K., Kafeza, E., \& Hung, P. C. (2011). ISF special issue on emerging social and legal aspects of information systems with Web 2.0. Information Systems Frontiers, 13(2), 153-155.

Culnan, M. J., McHugh, P. J., \& Zubillaga, J. I. (2010). How large U.S. companies can use twitter and other social media to gain business value. MIS Quarterly Executive, 9(4), 243-259.

Davis, F. D. (1989). Perceived usefulness, perceived ease of use, and user acceptance of information technology. MIS Quarterly, 13(3), 319340.

Davis, F. D., Bagozzi, R. P., \& Warshaw, P. R. (1989). User acceptance of computer technology: a comparison of two theoretical models. Management Science, 35(8), 982-1003.

Dernbecher, S., \& Beck, R. (2017). The concept of mindfulness in information systems research: a multi-dimensional analysis. European Journal of Information Systems, 26(2), 121-142.

Durand, R., \& Vaara, E. (2009). Causation, counterfactuals, and competitive advantage. Strategic Management Journal, 30(12), 12451264.

Dwivedi, Y. K., Kelly, G., Janssen, M., Rana, N. P., Slade, E. L., \& Clement, M. (2018). Social media: the good, the bad, and the ugly. Information Systems Frontiers, 20(3), 419-423.

Dwivedi, Y. K., Rana, N. P., Jeyaraj, A., Clement, M., \& Williams, M. D. (2019). Re-examining the unified theory of acceptance and use of technology (UTAUT): towards a revised theoretical model. Information Systems Frontiers, 21(3), 719-734.

El Sawy, O. A., Malhotra, A., YoungKi, P., \& Pavlou, P. A. (2010). Research commentary-seeking the configurations of digital ecodynamics: it takes three to tango. Information Systems Research, 21(4), 835-848.

Emmenegger, P., Schraff, D., \& Walter, A. (2014). QCA, the truth table analysis and large-N survey data: The benefits of calibration and the importance of robustness tests. In 2nd International QCA Expert Workshop, November, Zurich, Switzerland. Available at: https:// www.researchgate.net/profile/Dominik_Schraff/publication/ 305497059 QCA the Truth Table Analysis and Large-N Survey Data The Benefits of Calibration and the Importance of_Robustness_Tests/links/57921 ecd08aed51475ac23d3.pdf. Accessed 15 Nov 2017

Fiss, P. C. (2011). Building better causal theories: a fuzzy set approach to typologies in organization research. Academy of Management Journal, 54(2), 393-420.

Flick, U. (2009). An introduction to qualitative research. London: Sage Publications.

Forza, C. (2002). Survey research in operations management: a processbased perspective. International Journal of Operations \& Production Management, 22(2), 152-194.

Fuchs, C. (2014). Social media: A critical introduction. London: Sage Publications.

GDPR, General Data Protection Regulation (EU) 2016/679 of the European Parliament and of the Council of 27 April 2016 (Directive 95/46), 59 (2016) 1-88. Available at: https://ec.europa. eu/info/law/law-topic/data-protection_en. Accessed 17 Jan 2020.

Gefen, D., \& Straub, D. W. (2000). The relative importance of perceived ease-of-use in IS adoption: a study of e-commerce adoption. Journal of the Association for Information Systems, 1(1), 1-30.

George, A. L., \& Bennett, A. (2005). Case studies and theory development in the social sciences. Cambridge: MIT Press. 
Goertz, G., \& Mahoney, J. (2012). A tale of two cultures: Qualitative and quantitative research in the social sciences. Princeton: Princeton University Press.

Greckhamer, T., Misangyi, V. F., Elms, H., \& Lacey, R. (2008). Using qualitative comparative analysis in strategic management research: an examination of combinations of industry, corporate, and business-unit effects. Organizational Research Methods, 11(4), 695-726.

Günther O., Krasnova H., Riehle D., \& Schondienst V. (2009). Modeling microblogging adoption in the Enterprise. Paper presented at the Americas Conference on Information Systems (AMCIS), 6-9 August, San Francisco, CA. Available at: http://www.icsi.berkeley. edu/pubs/other/modelingmicroblogging09.pdf. Accessed 13 Sept 2016.

Haugh, H., \& McKee, L. (2004). The cultural paradigm of the smaller firm. Journal of Small Business Management, 42(4), 377-394.

Heidt, M., Gerlach, J. P., \& Buxmann, P. (2019). Investigating the security divide between SME and large companies: how SME characteristics influence organizational IT security investments. Information Systems Frontiers, 21(6), 1285-1305.

Henfridsson, O., \& Bygstad, B. (2013). The generative mechanisms of digital infrastructure evolution. MIS Quarterly, 37(3), 896-931.

Hogan, B., \& Quan-Haase, A. (2010). Persistence and change in social media. Bulletin of Science, Technology and Society, 30(5), 309-315.

Hu, T., Kettinger, W. J., \& Poston, R. S. (2015). The effect of online social value on satisfaction and continued use of social media. European Journal of Information Systems, 24(4), 391-410.

Huang, J., Baptista, J., \& Galliers, R. D. (2013). Reconceptualizing rhetorical practices in organizations: the impact of social media on internal communications. Information and Management, 50(2), $112-124$.

Iannacci, F., \& Cornford, T. (2018). Unravelling causal and temporal influences underpinning monitoring systems success: a typological approach. Information Systems Journal, 28(2), 384-407.

Järvinen, J., Tollinen, A., Karjaluo, H., \& Jayawardhena, C. (2012). Digital and social media marketing usage in $\mathrm{B} 2 \mathrm{~B}$ industrial section. The Marketing Management Journal, 22(2), 102-117.

Jussila, J. J., Kärkkäinen, H., \& Aramo-Immonen, H. (2014). Social media utilization in business-to-business relationships of technology industry firms. Computers in Human Behavior, 30(1), 606-613.

Kallinikos, J., Aaltonen, A., \& Marton, A. (2013). The ambivalent ontology of digital artifacts. MIS Quarterly, 37(2), 357-370.

Kane, G. C., Alavi, M., Labianca, G. J., \& Borgatti, S. P. (2014). What's different about social media networks? A framework and research agenda. MIS Quarterly, 38(1), 275-304.

Kaplan, A. M., \& Haenlein, M. (2010). Users of the world, unite! The challenges and opportunities of social media. Business Horizons, 53(1), 59-68.

Kapoor, K. K., Tamilmani, K., Rana, N. P., Patil, P., Dwivedi, Y. K., \& Nerur, S. (2018). Advances in social media research: past, present and future. Information Systems Frontiers, 20(3), 531-558.

Kim, D. H., Lee, I., \& Lee, C. H. (2013). Building web 2.0 enterprises: a study of small and medium enterprises in the United States. International Small Business Journal, 31(2), 156-174.

Kwayu, S., Lal, B., \& Abubakre, M. (2018). Enhancing organisational competitiveness via social media-a strategy as practice perspective. Information Systems Frontiers, 20(3), 439-456.

Leclercq-Vandelannoitte, A. (2015). Managing BYOD: how do organizations incorporate user-driven IT innovations? Information Technology \& People, 28(1), 2-33.

Lee, Y., Kozar, K. A., \& Larsen, K. R. T. (2003). The technology acceptance model: past, present, and future. Communications of the Association for Information Systems, 12(1), 752-780.

Leonardi, P. M., Huysman, M., \& Steinfield, C. (2013). Enterprise social media: definition, history, and prospects for the study of social technologies in organizations. Journal of Computer-Mediated Communication, 19(1), 1-19.

Levinthal, D., \& Rerup, C. (2006). Crossing an apparent chasm: bridging mindful and less-mindful perspectives on organizational learning. Organization Science, 17(4), 502-513.

Li, H., Troutt, M. D., Brandyberry, A., \& Wang, T. (2011). Decision factors for the adoption and continued use of online direct sales channels among SMEs. Journal of the Association for Information Systems, 12(1), 1-31.

Liu, Y., Mezei, J., Kostakos, V., \& Li, H. (2017). Applying configurational analysis to IS behavioural research: a methodological alternative for modelling combinatorial complexities. Information Systems Journal, 27(1), 59-89.

Mahoney, J., \& Vanderpoel, R. S. (2015). Set diagrams and qualitative research. Comparative Political Studies, 48(1), 65-100.

Mandal, D., \& McQueen, R. J. (2012). Extending UTAUT to explain social media adoption by microbusinesses. International Journal of Managing Information Technology, 4(4), 1-11.

March, J. G. (1991). Exploration and exploitation in organizational learning. Organization Science, 2(1), 71-87.

Mendel, J. M., \& Ragin, C. C. (2011). fsQCA: Dialog between Jerry M. Mendel and Charles C. Ragin. Available at: http://www.compasss. org/pages/resources/emailmendel.pdf. Accessed 9 Mar 2011.

Merali, Y., Papadopoulos, T., \& Nadkarni, T. (2012). Information systems strategy: past, present, future? Journal of Strategic Information Systems, 21(2), 125-153.

Michaelidou, N., Siamagka, N., \& T., \& Christodoulides, G. (2011). Usage, barriers and measurement of social media marketing: an exploratory investigation of small and medium B2B brands. Industrial Marketing Management, 40(7), 1153-1159.

Mingers, J. (2006). Realising systems thinking: Knowledge and action in management science. New York: Springer.

Nazir, S., \& Pinsonneault, A. (2012). IT and firm agility: an electronic integration perspective. Journal of the Association for Information Systems, 13(3), 150-171.

Overby, E., Bharadwaj, A., \& Sambamurthy, V. (2006). Enterprise agility and the enabling role of information technology. European Journal of Information Systems, 15(2), 120-131.

Paluch, S., Egbert, D., \& Blut, M. (2015). Acceptance of social media by organizational users- testing the impact of system design features. Paper presented at the International Conference on Information Systems (ICIS), 13-16 December, Fort Worth, Texas. Available at: http://aisel.aisnet.org/cgi/viewcontent.cgi?article=1678\&context= icis2015. Accessed 13 Sept 2016.

Park, Y., El Sawy, O. A., \& Fiss, P. C. (2017). The role of business intelligence and communication technologies in organizational agility: a configurational approach. Journal of the Association for Information Systems, 18(9), 648-686.

Poston, R. S., \& Kettinger, W. J. (2014). Mindfully experimenting with IT: cases on corporate social media introduction. Journal of Database Management, 25(2), 29-51.

Ragin, C. C. (1987). The comparative method: Moving beyond qualitative and quantitative strategies. Berkeley: University of California Press.

Ragin, C. C. (2000). Fuzzy-set social science. Berkeley: The University of Chicago Press.

Ragin, C. C. (2008). Redesigning social enquiry. Chicago: The University of Chicago Press.

Ragin, C. C. (2015). Qualitative comparative analysis workshop. Available at: https://gpc.stanford.edu/sites/default/files/ stanfordqcaworkshop2015.pdf. Accessed 17 Nov 2017.

Ragin, C., \& Davey, S. (2014). $f_{s} / Q C A$ [Computer program], version [2.5/3.0]. Irvine: University of California.

Richey, M., Gonibeed, A., \& Ravishankar, M. N. (2018). The perils and promises of self-disclosure on social media. Information Systems Frontiers, 20(3), 425-437. 
Rihoux, B., \& Lobe, B. (2009). The case for qualitative comparative Analysis (QCA): Adding leverage for thick cross-case comparison. In D. Byrne \& C. Ragin (Eds.), The sage handbook of case-based methods (pp. 222-242). London: Sage Publications.

Rivard, S., \& Lapointe, L. (2012). Information technology implementers' responses to user resistance: nature and effects. MIS Quarterly, 36(3), 897-920.

Rogers, E. M. (2003). Diffusion of innovations (5th ed.). New York: Free Press.

Saga, V. L., \& Zmud, R. W. (1993). The nature and determinants of IT acceptance, routinization, and infusion. In L. Levine (Ed.), Proceedings of the IFIP TC8 working conference on diffusion, transfer and implementation of information technology (pp. 6786). North-Holland: Elsevier Science.

Schlagwein, D., \& Hu, M. (2017). How and why organizations use social media: five use types and their relation to absorptive capacity. Journal of Information Technology, 32(2), 194-209.

Schneider, C. Q. (2019). Two-step QCA revisited: the necessity of context conditions. Quality \& Quantity, 53(3), 1109-1126.

Schneider, C. Q., \& Wagemann, C. (2012). Set-theoretic methods for the social sciences: A guide to qualitative comparative Analysis. Cambridge: Cambridge University Press.

Schneider, C. Q., \& Wagemann, C. (2016). Assessing ESA on what it is designed for: a reply to Cooper and Glaesser. Field Methods, 28(3), 316-321.

Shen, A. X., Cheung, C. M., Lee, M. K., \& Chen, H. (2011). How social influence affects we-intention to use instant messaging: the moderating effect of usage experience. Information Systems Frontiers, 13(2), 157-169.

Siamagka, N. T., Christodoulides, G., Michaelidou, N., \& Valvi, A. (2015). Determinants of social media adoption by B2B organizations. Industrial Marketing Management, 51(1), 89-99.

Srinivasan, R., Lilien, G. L., \& Rangaswamy, A. (2002). Technological opportunism and radical technology adoption: an application to ebusiness. Journal of Marketing, 66(3), 47-60.

Straub, D. W. (2012). Editorial: does MIS have native theories? MIS Quarterly, 36(2), iii-xii.

Straub, D. W., Boudreau, M. C., \& Gefen, D. (2004). Validation guidelines for IS positivist research. Communications of the Association for Information Systems, 13(1), 380-427.

Sue, V. M., \& Ritter, L. A. (2012). Conducting online surveys. Los Angeles: Sage Publications.

Sun, H. (2012). Understanding user revisions when using information systems features: adaptive systems use and triggers. MIS Quarterly, 36(2), 453-478.

Swanson, E. B., \& Ramiller, N. C. (2004). Innovating mindfully with information technology. MIS Quarterly, 28(4), 553-583.

Thatcher, J. B., Wright, R. T., Sun, H., Zagenczyk, T. J., \& Klein, R. (2018). Mindfulness in information technology use: definitions, distinctions, and a new measure. MIS Quarterly, 42(3), 831-847.

Trinh-Phuong, T., Molla, A., \& Peszynski, K. (2012). Enterprise systems and organizational agility: a review of the literature and conceptual framework. Communications of the Association for Information Systems, 31(1), 167-193.

Vaast, E., \& Kaganer, E. (2013). Social media affordances and governance in the workplace: an examination of organizational policies. Journal of Computer-Mediated Communication, 19(1), 78-101.

Venkatesh, V., \& Davis, F. D. (2000). A theoretical extension of the technology acceptance model: four longitudinal field studies. Management Science, 46(2), 186-204.

Venkatesh, V., Thong, J. Y., Chan, F. K., Hu, P. J. H., \& Brown, S. A. (2011). Extending the two-stage information systems continuance model: incorporating UTAUT predictors and the role of context. Information Systems Journal, 21(6), 527-555.

Wang, W. Y., Pauleen, D. J., \& Zhang, T. (2016). How social media applications affect B2B communication and improve business performance in SMEs. Industrial Marketing Management, 54(1), 4-14.

Weick, K. E., \& Sutcliffe, K. M. (2007). Managing the unexpected: Resilient performance in an age of uncertainty. San Francisco: Wiley.

Weick, K. E., Sutcliffe, K. M., \& Obstfeld, D. (1999). Organizing for high reliability: Processes of collective mindfulness. In Sutton, R. S. \& Staw, B. M. (Eds.), Research in organizational behavior, Volume 1 (pp. 81-123). Stanford: Jai Press.

Whelan, E., Teigland, R., Vaast, E., \& Butler, B. (2013). Editorial: interpreting digitally enabled social networks. Information Systems Journal, 23(6), 471-474.

Wisniewski, P., Xu, H., \& Chen, Y. (2014). Understanding user adaptation strategies for the launching of Facebook timeline, paper presented at the 32nd annual ACM Conference on Human Factors in Computing Systems, 26 April-1 May, Toronto, Canada. Available at: https://faculty.ist.psu.edu/xu/papers/chi2014Facebook.pdf. Accessed 13 Mar 2016.

Yin, R. K. (2014). Case study research: Design and methods. Thousand Oaks: Sage Publications.

Zhao, J. L., Tanniru, M., \& Zhang, L. J. (2007). Services computing as the foundation of enterprise agility: overview of recent advances and introduction to the special issue. Information Systems Frontiers, 9(1), 1-8.

Publisher's Note Springer Nature remains neutral with regard to jurisdictional claims in published maps and institutional affiliations.

Dr Federico lannacci is a Lecturer in Digital Technology at Work at the University of Sussex and a Visiting Fellow at Kent Business School (University of Kent). Dr. Iannacci is currently serving as an AE for the Information Systems Journal (ISJ) and has previously served as an AE for the European Conference on Information Systems (ECIS) and as a Track Chair for the Italian Association for Information Systems. His research has appeared in journals such as the European Journal of Information Systems, Information Systems Journal, Information \& Organization, the Journal of Information Technology and the Journal of Strategic Information Systems.

Dr Colm Fearon is currently a Senior Lecturer in Business Education at the University of Birmingham (UK). He has previously taught information systems subjects for several years at the Queen's University of Belfast (Northern Ireland), in areas such as: database design; datawarehousing; IT for business/ consultancy; systems analysis, design and project management. Colm has also co-authored publications in several leading information systems outlets, including: The Journal of Information Technology (JIT); European Journal of Information Systems (EJIS); Internet Research; Behaviour and Information Technology; British Journal of Educational Technology.

Kristine Pole is a Senior Lecturer in Marketing with an interest in social media and public relations. She teaches Public Relations at Canterbury Christ Church University and has worked with Cision.com in a research capacity on the global role of social media use between journalism and PR. Kristine is a research consultant with Vuelio.com investigating influencer marketing. Her additional research interests are focused on the pedagogy of role-play simulations in Crisis Management. 